УДК 550.4.02

\title{
ВЛИЯНИЕ МИКРОЭЛЕМЕНТНОГО СОСТАВА УГЛЕРОДСОДЕРЖАЩИХ ПОРОД НА ВОЗМОЖНОСТЬ ИХ ИСПОЛЬЗОВАНИЯ В ВОДООЧИСТКЕ (НА ПРИМЕРЕ ШУНГИТОВ ИЗ ОНЕЖСКОЙ ПАЛЕОПРОТЕРОЗОЙСКОЙ СТРУКТУРЫ КАРЕЛИИ)
}

\author{
Кондрашова Наталья Ивановна ${ }^{1,2}$, \\ kondr@krc.karelia.ru
}

\author{
Медведев Павел Владимирович1,2, \\ pmedved@krc.karelia.ru \\ 1 Петрозаводский Государственный университет, \\ Россия, 185910, г. Петрозаводск, пр. Ленина, 33. \\ 2 Карельский научный центр РАН, \\ Россия, 185910, г. Петрозаводск, ул. Пушкинская, 11
}

\begin{abstract}
Актуальность исследования обусловлена необходимостью получения непротиворечивой инфрормации о возможности использования углеродсодержащих осадочных пород шунгитов для очистки питьевой воды. В настоящее время шунгиты используются во многих отраслях промышленности, доказана их эффрективность при очистке сточных вод от органических веществ и нефттепродуктов. Учитывая высокую адсорбиионную способность иундитов, отдельные исследователи без должных на то оснований, рекомендуют использовать их для очистки вод хозяйственно-питьевого водопользования.

Цель: изучить микроэлементньй состав шунгитов, оценить возможность поступления вредных для человека микроэлементов в водный раствор шунаита.

Объекты: образцы шунгитов из палеопротерозойских разрезов Онежской синклинальной структуры, Карелия. Методика: электронная микроскопия, химический анализ, масс-спектрометрия с индуктивно-связанной плазмой (ICP-MS). Результаты. Изучен макро- и микроэлементный состав шунаитов палеопротерозойской Онежской структуры (Карелия). Их минеральный состав представлен преимущественно кварцем (25-65 \%), серицитом, хлоритом, пиритом, встречается карбонат, содержание свободного углерода составляет 21-45 \%. Пирит присутствует как в форме нодулей, так и в микропрожилках. Помимо пирита отмечены сульфиды цинка, кобальтин, окислы свинца. Макроэлементы (Si, Ti, Al, Fe, Mn, Ca, Mg, Na, K), обнаруживаемые в химическом составе шунаитов, входят преимущественно в состав породообразующих минералов. Помимо макроэлементов, в шунгитах содержится значительное число микроэлементов, связанных с акцессорными минералами и сульфридами различной размерности. Это S, As, V, Co, $\mathrm{Ni}, \mathrm{Cr}, \mathrm{Cu}, \mathrm{Zn}, \mathrm{Mo}, \mathrm{Ge}, \mathrm{B}, \mathrm{Sr}, \mathrm{Li}, \mathrm{Pb}$, редкоземельные элементы. B шунгитах Зажогинского месторождения содержания хрома составляют от 96 до 151 2/m, содержания никеля - от 102 до 259 2/m. В углеродсодержащих породах Максово хром присутствует в количестве 103-144 2/m, концентрации никеля определены 8 интервале 47-196 2/m. Для месторождения Шуньга эти значения следующие: Cr nрисутствует в количестве 74-137 2/m, coдержание Ni равно 86-275 г/m. Шунгиты, обладая высокой сорбционной способностью, могут поглощать вредные компоненты из воды. Благодаря данному свойству их предлагают использовать в водоочистке питьевой воды. Не следует забывать, что одновременно происходит и обратный процесс - экстрагирование в воду из шунгитов вредных для человека примесных элементов. Существующие в настоящее время способы очистки не позволяют удалить микропримеси, поэтому вопрос об использовании шунгитов для водоподготовки с целью питьевого водоснабжения остается открытым.
\end{abstract}

\section{Ключевые слова:}

Шунгит, микроэлементный состав, Карелия, Онежская синклинальная структура, людиковий, палеопротерозой.

\section{Введение}

Углеродсодержащие осадочные породы в Карелии впервые были описаны как углистые сланцы в XVIII в. Н.Я. Озерецковским, но только в ХІХ в., после работ А.А. Иностранцева, получили собственное название «шунгиты», ставшее в наши дни довольно известным. А.А. Иностранцев описал четыре разновидности углеродсодержащих пород, одну из которых, обнаруженную им в районе д. Шуньга, предложил называть шунгитом. Но позднее это название стали применять ко всем углеродсодержащим породам, обнаруженным в Карелии (рис. 1).

Шунгитовые породы в Онежском синклинории, где расположены их месторождения и большинство рудопроявлений, приурочены к трем стратиграфическим уровням палеопротерозоя - людиковию, калевию и вепсию (рис. 2).
В состав людиковийского надгоризонта входят карбонатные, терригенные и вулканогенные породы. Встречаются многочисленные силлы габбро-долеритов. Калевийский и вепсийский надгоризонты представлены преимущественно осадочными терригенными породами. На разных уровнях разрезов указанных надгоризонтов встречаются слои и пачки углеродсодержащих сланцев, алевролитов и песчаников. Основной объем шунгитов приурочен к людиковийскому и частично калевийскому надгоризонтам $[4,6,7]$.

Мощность слоев шунгитовых пород варьирует в широких пределах, так же как содержание в них углерода и состав вмещающих шунгиты пород. Отмечается циклическое чередование безуглеродистых и шунгитовых отложений. В основании таких циклитов развиты бесшунгитовые (или с небольшим количеством прослоев шунгитовых пород) карбонат- 
кварц-слюдистые породы, которые выше сменяются шунгитсодержащими породами. Вверх по разрезу людиковия происходит увеличение содержания уг- лерода в породах. В этом направлении возрастает также количество туфогенного и кремнистого вещества [8].

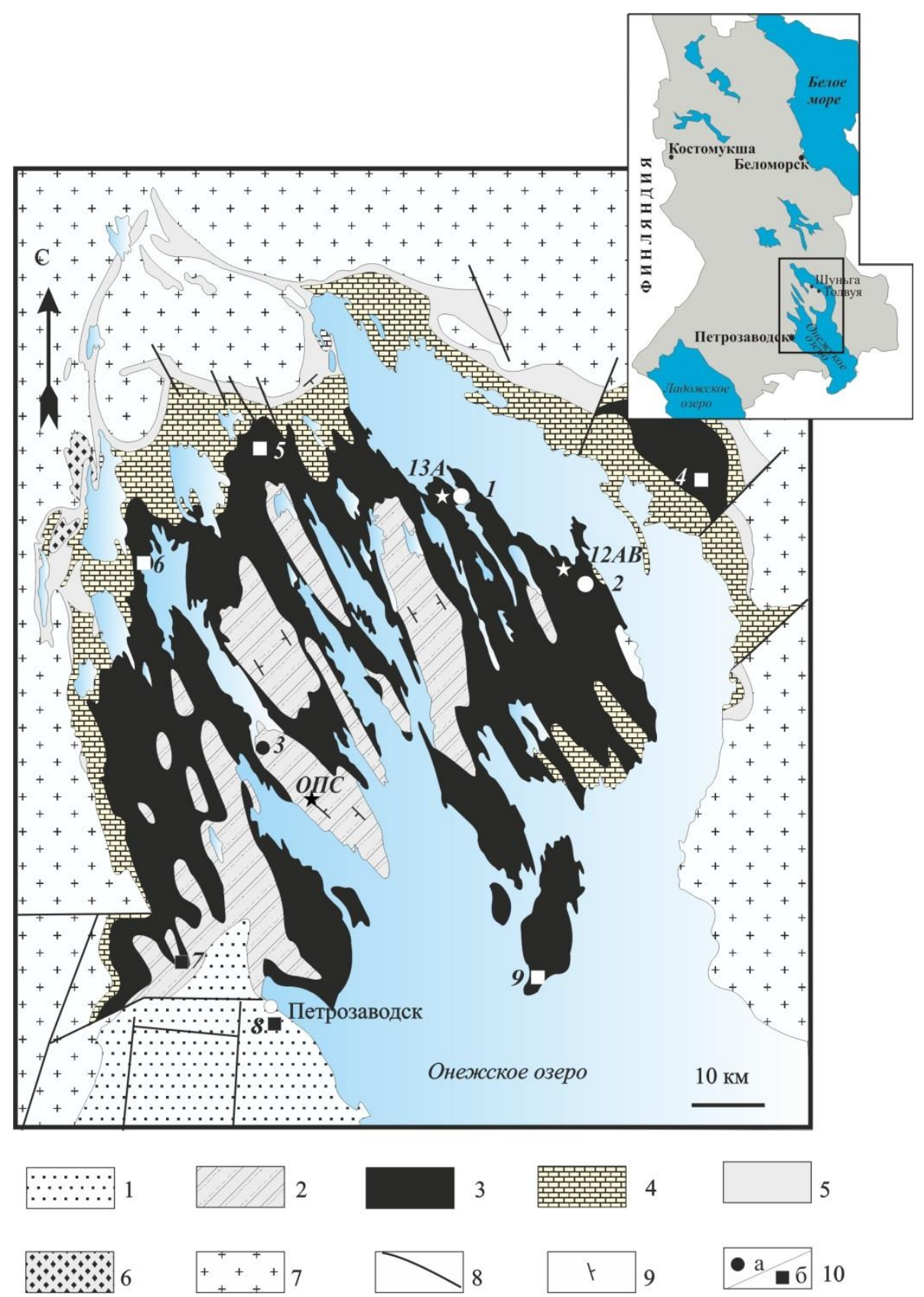

Рис. 1. Геологическая схема Онежского синклинория [1] с местоположением месторождений и отдельных рудопроявлений шунгитовых пород [2]. 1 - вепсийский надгоризонт; 2 - калевийский надгоризонт; 3 - людиковийский надгоризонт; 4, 5 - ятулийский надгоризонт (4-онежский горизонт; 5 - сегозерский горизонт); 6 - сариолийский надгоризонт; 7 - архейский фундамент; 8 -разрывные нарушения; 9 - элементы залегания слоистости; 10 - шунгитовые: а -месторождения, $\sigma$ - рудопроявления. Звездочками показано местоположение скважин проекта FAR-DEEP [3] и Онежской параметрической скважины (ОПC) [4]. На врезке указано расположение Онежского синклинория. Шунгитовые месторождения: 1 - Шуньгское, 2 - Зажогинское, 3 - Нигозерское. Рудопроявления: 4 - Кочкомское, 5 - Пролетарка, 6 - Лычноостровское, 7 - Чевжавара-1, 8 - Петрозаводское, 9 - остров Березовеи

Fig. 1. Geological sketch map of the Onegian paleobasin [1] with the location of deposits and individual ore occurrences of shungite rocks [2]. 1 - Vepsian group; 2 - Kalevian group; 3 - Ludikovian group; 4, 5 - Yatulian group (4 - Onegian formation; 5 -Segozerian formation); 6 - Sariolian group; 7 - Archean basement; 8 -faults; 9 - dip and strike; 10 - shungite: $a$-deposits, $b$-ore occurrences. The asterisks show the location of the FAR-DEEP drill holes [3] and the Onegian parametric drill hole [4]. The inset shows the location of the Onegian paleobasin. Shungite deposits: 1 - Shungskoe, 2 - Zazhoginskoe, 3 - Nigozerskoe. Ore occurrences: 4 - Kochkomskoe, 5 - Proletarka, 6 - Lychnoostrovskoe, 7 - Chevzhavara-1, 8-Petrozavodskoe, 9 - Berezovets Island 


\begin{tabular}{|c|c|c|c|c|}
\hline Эонотема & Эратема & $\begin{array}{l}\text { Возраст } \\
\text { границ } \\
\text { млн лет } \\
\end{array}$ & $\begin{array}{c}\text { Типовые стратиграфические } \\
\text { подразделения (надгоризонты) } \\
\text { региональной шкалы }\end{array}$ & $\begin{array}{c}\text { Местные стратиграфические } \\
\text { подразделения } \\
\text { (свиты, Онежский синклинорий) }\end{array}$ \\
\hline \multirow{6}{*}{ 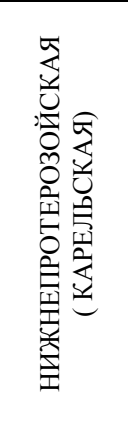 } & \multirow{3}{*}{$\begin{array}{l}\text { Верхне- } \\
\text { карельская }\end{array}$} & 1800 & Вепсийский & $\begin{array}{c}\text { шокшинская } \\
\text { петрозаводская }\end{array}$ \\
\hline & & 1920 & Калевийский & $\begin{array}{c}\text { вашозерская } \\
\text { кондопожская }\end{array}$ \\
\hline & & 2100 & Людиковийский & $\begin{array}{c}\text { суйсарская } \\
\text { заонежская }\end{array}$ \\
\hline & \multirow{3}{*}{$\begin{array}{l}\text { Нижне- } \\
\text { карельская }\end{array}$} & 2300 & Ятулийский & $\begin{array}{c}\text { туломозерская } \\
\text { медвежьегорская } \\
\text { янгозерская } \\
\end{array}$ \\
\hline & & 2400 & Сариолийский & пальеозерская \\
\hline & & 2500 & Сумийский & $\begin{array}{c}\text { кумсинская } \\
\text { глубокоозерская }\end{array}$ \\
\hline
\end{tabular}

Рис. 2. Расчленение нижнего протерозоя Карелии в общей стратиграфической шкале докембрия России [5]

Fig. 2. Lower Proterozoic subdivisions of Karelia in the general stratigraphic scale of the Precambrian of Russia [5]

Шунгиты обладают целым рядом таких свойств (экранирующие свойства, электропроводность, адсорбционные свойства и др.), которые позволяют найти им применение во многих отраслях экономики: в металлургической и химической промышленности, строительстве, сельском хозяйстве, медицине [9-15].

Помимо этого, шунгиты - благодатный материал для научных исследований. Изучение стабильных изотопов серы, органического и карбонатного углерода позволяет геологам аргументированно судить об особенностях осадконакопления, о климате, содержании кислорода в атмосфере и в воде морских бассейнов в палеопротерозойское время [16-24].

Запасы шунгитов в Карелии оцениваются в несколько миллиардов тонн $[2,7]$.

Углеродсодержащие образования, к которым относятся шунгиты, - горные породы, содержащие некристаллический природный не графитизируемый углерод [25], не уникальны. Подобные породы встречаются в Южной и Центральной Африке, Австралии и Северной Америке [26-28]. В России, помимо Карелии, Кольского полуострова, углеродсодержащие осадочные породы известны в Сибири, в Воронежском массиве, на Урале, Таймыре, Саянах и во многих других районах, подтверждая высказанную почти 70 лет назад точку зрения, что «углеродистая составляющая», «углеродистая компонента», является обязательной для всех первично-осадочных образований докембрия [8].

В дискуссионном геологическом поле появляются работы об использовании шунгитов для очистки питьевой воды $[9,10]$, для удаления из воды бактериальной микрофлоры $[29,30]$.

Надо отдать должное многим авторам, упоминающим о присутствии в шунгитах минеральных примесей [31], вхождении токсикантов в кристаллическую решетку минералов углеродсодержащих пород [32]. В некоторых работах указываются способы борьбы с ними [17, 33, 34].

Однако приводимые в указанных работах примеры не настолько убедительны, чтобы делать вывод о безопасности очистки питьевой воды при помощи шунгитовых фильтров.
Целью данной статьи является рассмотрение состава углеродсодержащих пород Онежской структуры и оценка возможных последствий их использования для очистки питьевой воды.

\section{Методы, материалы исследования}

В статье использованы материалы, полученные в ходе выполнения проекта FAR-DEEP Международной программы научного континентального бурения (ICDP) в 2007-2012 гг., а также материалы полевых исследований 2015-2019 гг.

Отобранные с различных уровней разреза людиковия образцы углеродсодержащих пород изучены на сканирующем электронном микроскопе и проанализированы традиционным методом «мокрой» химии, а также масс-спектрометрическим методом индуктивно-связанной плазмы (ICP-MS).

Состав минералов шунгитовых пород определялся на сканирующем растровом электронном микроскопе TESCAN VEGA II LSH с приставкой INCA Emergy 350 , совмещенной с микроанализатором (аналитик А.Н. Терновой) в Аналитическом центре Карельского научного центра РАН. Концентрации редких и редкоземельных элементов определялись на квадрупольном масс-спектрометре X-SERIES 2 (аналитик А.С. Парамонов) там же.

Используемые в работе химические анализы петрогенных элементов (силикатный анализ) выполнены в аналитической лаборатории Института геологии Кар НЦ РАН.

\section{Обсуждение и результаты исследования}

При исследовании шунгитов используют два определения данного термина. Одна часть исследователей определяет шунгит как некристаллический природный неграфитизируемый углерод.

Другая часть исследователей считает, что шунгит это осадочная порода, в составе которой присутствует углеродистое вещество.

Само название «шунгит» собирательное, т. к. под общим названием объединены породы, различающиеся как по содержанию углерода, так и по содержанию и составу примесного материала. Состав приме- 
сей может быть кремнистый, алюмосиликатный, карбонатный или смешанный.

Классификации шунгитов, удовлетворяющей всех исследователей, в настоящее время не разработано. Вероятно, первой классификацией, имеющей чисто геолого-историческое значение, следует назвать разделение углеродсодержащих пород Карелии по внешнему облику и физическим свойствам на 4 группы, выполненное А.А. Иностранцевым в 1879 г.

В 1956 г. опубликована классификация шунгитовых пород П.А. Борисова, которая используется рядом исследователей до настоящего времени [35]. П.А. Борисов, выделяя 5 разновидностей: шунгит I-V за основной классификационный признак взял содержание в породе углерода и, как следствие, количество минерального компонента (табл. 1).

Таблица 1. Классификация шунгитовых пород, предложенная П.А. Борисовым (1956)

Table 1. Classification of shungite rocks proposed by P.A. Borisov (1956)

\begin{tabular}{|l|c|c|c|c|c|}
\hline $\begin{array}{l}\text { Разновидности шунгитовых пород } \\
\text { Varieties of shungite rocks }\end{array}$ & I & II & III & IV & V \\
\hline $\begin{array}{l}\text { Содержание углерода, \% } \\
\text { С content, \% }\end{array}$ & 98 & 60 & 35 & 20 & $5-10$ \\
\hline $\begin{array}{l}\text { Содержание золы, \% } \\
\text { Ash content, \% }\end{array}$ & 2 & 40 & 65 & 80 & $90-95$ \\
\hline
\end{tabular}

Претензии исследователей, занимающихся исследованием шунгитов, предъявляемые к простой и изящной классификации А.П. Борисова, состоят в том, что она не учитывает состав минеральной основы, типы пород и генезис органического вещества. Следствием данного обстоятельства стало появление других классификаций: Л.П. Галдобиной с коллегами в 1975 г., В.И. Горлова в 1984 г., Ю.И. Калинина в 1984 г. В 2002 г. М.М. Филиппов предлагает подразделять шунгиты на основе типа шунгитового вещества [36]. Самый высокий ранг в генетической классификации М.М. Филиппова принадлежит группе (группа 1 - сапропелитовые породы, группа 2 - сапробитумолитовые породы, группа 3 - битумолитовые породы, группа 4 - переотложенные сапробитумолитовые породы).

Подразделение шунгитовых пород, предложенное M.М. Филиповым, можно провести только после значительного объема лабораторных исследований, но даже при этом полученные выводы могут быть неоднозначны. Поэтому, несмотря на недостатки, классификация П.А. Борисова продолжает и сегодня оставаться востребованной.

Широкое внимание к шунгитам не в последнюю очередь определяется их необычной структурой. По данным В.В. Ковалевского [37] она напоминает структуру стеклокристаллических материалов, когда высокодисперсные кристаллы распределены в некристаллической матрице. В шунгитовых породах роль некристаллической матрицы выполняет шунгит, в котором минеральные компоненты присутствуют в виде микрокристаллов, размерами в среднем около 1 мкм, нанокристаллов (до 10 и менее нм), а также углеродсодержащих слоев и кластеров.
Коллектив авторов в своей, ставшей в настоящее время классической, работе, основываясь на величине показателя $(\mathrm{H} / \mathrm{C}=0,0015-0,0050)$, впервые указал на близость шунгита к стеклоуглероду [38].

Исследования последних лет показали, что шунгит является специфичной формой углерода, представляющей собой некристаллический, неграфитируемый, фуллереноподобный углерод, отличающийся от графитового на уровне надмолекулярной, атомной и зонной (электронной) структуры $[11,37]$.

Именно по своей структурной специфичности, оцениваемой по величине приведенной энергии активации $\mathrm{E}_{0}$, шунгит, или шунгитовый углерод, отличается от графита. Для шунгитового углерода величина $\mathrm{E}_{0}<4,70$ ккал/моль, для графитоидов этот показатель

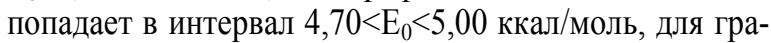
фитов величина $\mathrm{E}_{0}>5,00$ [38]. По данным [8] для шунгитов зафиксировано понижение сравнительной степени упорядоченности структуры от минимальной (пос. Нигозеро) через промежуточную (пос. Максово) к максимальной (пос. Шуньга) (рис. 1).

Месторождения шунгитов в Онежском синклинории приурочены к верхней подсвите заонежской свиты, включённой в состав людиковийского надгоризонта палеопротерозоя Карелии (рис. 1, 2). Подсвита разделена на пачки, мощность которых варьирует от 140 до 340 м и которые содержат тела высокоуглеродистых пород. Шунгиты являются верхней частью осадочных циклов, нижняя часть циклов сложена туфами. На Зажогинском месторождении количество таких циклов меняется от трех в нижней осадочной пачке до шести в верхней пачке. В пределах каждого месторождения и рудопроявления шунгитов присутствуют силлы габбро-долеритов. На Зажогинском месторождении их количество достигает десяти, все они приурочены к контактам туфов и высокоуглеродистых пород [2].

Минералы шунгитов представлены кварцем (25-65 \%), серицитом, хлоритом, пиритом, встречается карбонат. Свободный углерод содержится в количестве 21-45 \%, Пирит присутствует как в форме нодулей, так и в микропрожилках (рис. 3,4 ).

Макроэлементы ( $\mathrm{Si}, \mathrm{Ti}, \mathrm{Al}, \mathrm{Fe}, \mathrm{Mn}, \mathrm{Ca}, \mathrm{Mg}, \mathrm{Na}, \mathrm{K}$ ), обнаруженные в химическом составе шунгитов, входят главным образом в состав породообразующих минералов.

По данным бурения по проекту FAR-DEEP [3] в разрезе заонежской свиты (людиковий) Онежской структуры породы, обогащенные органическим углеродом, обнаружены на 4 уровнях разреза. Химический состав шунгитов, вскрытых скважиной $12 \mathrm{AB}$ в интервале 156,0-132,9 м при содержании $\mathrm{C}_{\text {орг }}$ $32,8-40,7 \%$, следующий: $\mathrm{SiO}_{2}-33,6-42,5 \%, \mathrm{Al}_{2} \mathrm{O}_{3}-$ $5-8 \%, \mathrm{Fe}_{2} \mathrm{O}_{3}-2,5-6,9 \%, \mathrm{MgO}-0,8-2,4 \%, \mathrm{~K}_{2} \mathrm{O}-$ 1,8-3 \%. В интервале глубин 56-31 м шунгиты $\left(\mathrm{C}_{\text {орг }}=23-26,7 \%\right)$ содержат $\mathrm{SiO}_{2}-57-62,8 \%, \mathrm{Al}_{2} \mathrm{O}_{3}-$ $4,1-5,4 \%, \mathrm{Fe}_{2} \mathrm{O}_{3}-0,8-6,4 \%, \mathrm{MgO}-0,9-1,1 \%, \mathrm{~K}_{2} \mathrm{O}-1,2-2,6 \%$.

Изучение керна скважины 13A проекта FAR-DEEP показало присутствие шунгитового материала в песчаниках $\left(\mathrm{C}_{\text {орг }}=1,6-28 \%\right)$ следующего химического состава: $\mathrm{SiO}_{2}-33-66 \%, \mathrm{Al}_{2} \mathrm{O}_{3}-8-14 \%, \mathrm{~K}_{2} \mathrm{O}-3,3-4,7 \%$, $\mathrm{Na}_{2} \mathrm{O}-0,2-1 \%, \mathrm{~S}-1,1-6,6 \%$. 


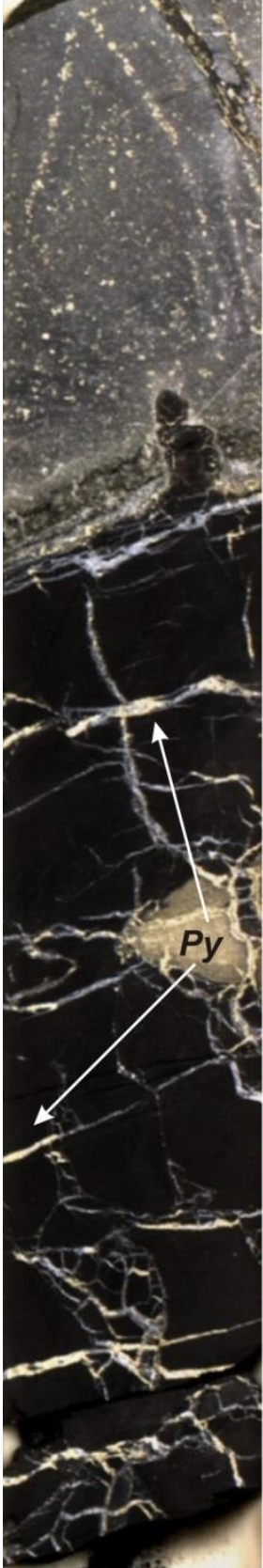

a / a

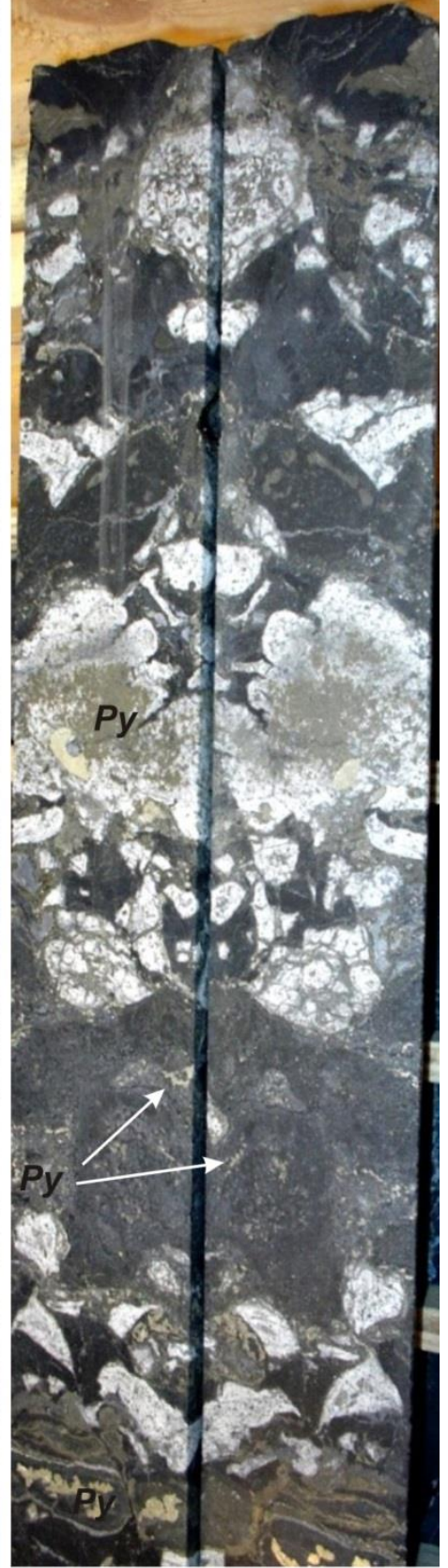

б / b
Рис. 3. Высокоуглеродистая порода (C>20\%) с пиритом в форме нодулей и микропрожилков (а) и шунгитсодержаший алевролит $(C<10 \%)$ с пиритом (б)

Fig. 3. Carbon rich rock $(C>20 \%)$ with pyrite nodules and microveins (a) and shungite-bearing siltstone $(C<10 \%)$ with pyrite $(b)$

В кремнистых породах (лидитах) с содержанием $\mathrm{SiO}_{2}-77-94 \%, \mathrm{Al}_{2} \mathrm{O}_{3}-0,08-2,2 \%, \mathrm{~K}_{2} \mathrm{O}-0,04-1 \%$ органического углерода содержится 3-9,3 весовых \%.

Обобщение всех имеющихся данных [2] показало следующий химический состав шунгитов Шуньгского месторождения: C - 41,0-61,34 \% (ср. 49,44 \%), S в среднем 4,5\%, P - 0,13-0,31\%, As - 0,04-0,09\%. Содержание в золе шунгитов ванадия в целом по месторождению равно 0,48 \%. Таким образом, в шунгитах помимо макроэлементов содержится значитель- ное число микроэлементов (табл. 2). Это не только $\mathrm{S}$, $\mathrm{As}, \mathrm{V}$, содержания которых приведены выше, но и $\mathrm{Co}$, $\mathrm{Ni}, \mathrm{Cr}, \mathrm{Cu}, \mathrm{Zn}, \mathrm{Mo}, \mathrm{Ge}, \mathrm{B}, \mathrm{Sr}, \mathrm{Li}, \mathrm{Pb}$, редкие земли, связанные с акцессорными минералами и сульфидами $[39,40]$.

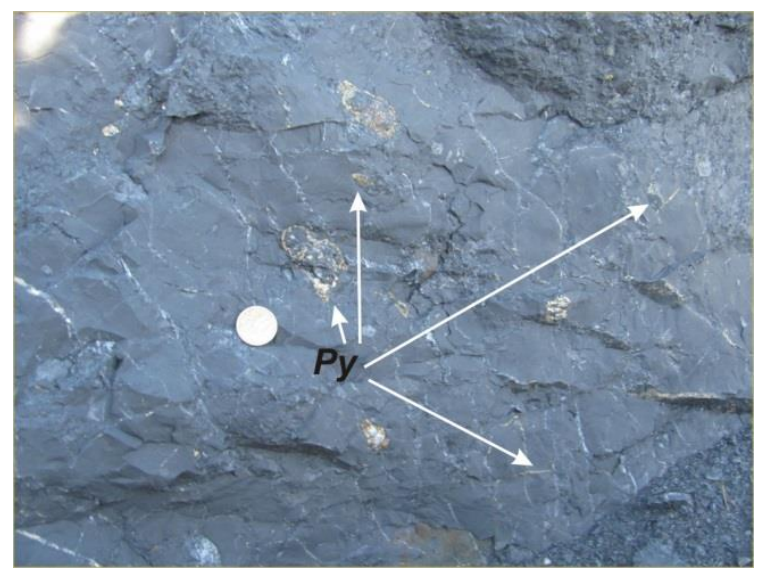

Pис. 4. Нодули и микропрожилки пирита в шунгите Зажогинского месторождения

Fig. 4. Pyrite nodules and micro-veins in shungite of the Zazhoginsky deposit

Таблица 2. Содержание некоторых микроэлементов $(2 / m)$ в отдельных разновидностях шунгитов разных районов Онежской структуры

Table 2. Content of some trace elements ( varieties of shungite from different occurrences of the Onegian paleobasin

\begin{tabular}{|c|c|c|c|c|c|c|c|c|c|c|}
\hline $\begin{array}{r}\text { Микро- } \\
\text { элементы } \\
(\mathrm{\Gamma} / \mathrm{T}) \\
\text { Trace } \\
\text { elements } \\
\text { (ppm) } \\
\text { Paйoн } \\
\text { Occurrence }\end{array}$ & $\mathrm{Cr}$ & V & Co & $\mathrm{Ni}$ & $\mathrm{Cu}$ & $\mathrm{Zn}$ & $\mathrm{Li}$ & $\mathrm{Rb}$ & Cs & 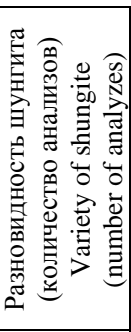 \\
\hline \multirow{2}{*}{$\begin{array}{c}\text { Зажогино } \\
\text { Zazhogino }\end{array}$} & 151 & 375 & 20 & 259 & 24 & 137 & - & - & - & II (6) \\
\hline & 96 & 263 & 8 & 102 & 40 & 16 & - & - & - & III (4) \\
\hline \multirow{3}{*}{$\begin{array}{c}\text { Карнаволок } \\
\text { Karnavolok }\end{array}$} & 62 & 202 & 8 & 55 & 40 & 32 & 19 & - & - & II (14) \\
\hline & 75 & 213 & 8 & 55 & 16 & 16 & 46 & - & - & III(19) \\
\hline & 171 & 319 & 16 & 236 & 16 & 24 & - & - & - & IV (3) \\
\hline \multirow{3}{*}{$\begin{array}{l}\text { Лебещина } \\
\text { Lebeshchina }\end{array}$} & 82 & 196 & 16 & 39 & 40 & 104 & - & - & - & II (1) \\
\hline & 103 & 202 & 16 & 71 & 56 & \begin{tabular}{|l|}
88 \\
\end{tabular} & 9 & 9 & 1 & III (32) \\
\hline & 96 & 207 & 16 & 102 & 48 & 64 & 9 & 9 & 1 & IV (10) \\
\hline \multirow{5}{*}{$\begin{array}{l}\text { Максово } \\
\text { Maksovo }\end{array}$} & 108 & 123 & $<79$ & \begin{tabular}{|l|}
69 \\
\end{tabular} & 18 & 370 & 8 & - & - & Ш (37) \\
\hline & 144 & 2818 & - & 196 & 72 & 265 & 5 & 18 & 2 & II (5) \\
\hline & 103 & 162 & - & 47 & 24 & \begin{tabular}{|l|}
88 \\
\end{tabular} & 9 & 18 & 1 & III (38) \\
\hline & 103 & 162 & - & 47 & 24 & 88 & 9 & 18 & 1 & IV (33) \\
\hline & - & - & - & - & - & 161 & - & -4 & - & V (3) \\
\hline \multirow{4}{*}{$\begin{array}{c}\text { Шуньга } \\
\text { Shunga }\end{array}$} & 34 & 913 & 16 & 275 & 104 & 289 & - & - & - & I (1) \\
\hline & 137 & 1036 & 8 & 196 & 64 & 96 & 88 & 9 & 2 & II (5) \\
\hline & 137 & 1188 & 24 & 212 & 80 & 137 & 19 & 27 & 1 & II (18) \\
\hline & 96 & 952 & 16 & 86 & 88 & 88 & - & -1 & - & III (2) \\
\hline
\end{tabular}

Примечание: «-»-нет данных

Note: «-»- no data

В разрезе, вскрытом скважинами 12А и 12В, встречен 80 см интервал шунгитовых прожилков с содержаниями Мо до 376 г/т, V до 1730 г/т, Ni до 510 г/T, U 53,3 г/T. 
По микротрещинкам в шунгите могут встречаться тонкодисперсные выделения ярозита.

Как видим из приведенных данных по составу шунгитов, они содержат вредные для человека микроэлементы, содержащиеся главным образом в сульфидах и акцессорных минералах размерностью от сотен до нескольких микрон (рис. 5).

При взаимодействии с водой пирита $\left(\mathrm{FeS}_{2}\right)$ образуется серная кислота, что ведет к снижению $\mathrm{pH}$. Об- разование $\mathrm{H}_{2} \mathrm{SO}_{4}$ облегчает экстракцию микроэлементов, содержащихся в шунгите.

По данным [29, 33] в кислой среде $(\mathrm{pH}=2-2,5)$ наиболее эффективно происходит процесс экстрагирования макро- и микроэлементов, в том числе лантаноидов, из шунгита в воду.

Эти же авторы [29] указывают на переход в раствор при контакте шунгит-вода до 60 химических элементов от лития до урана.

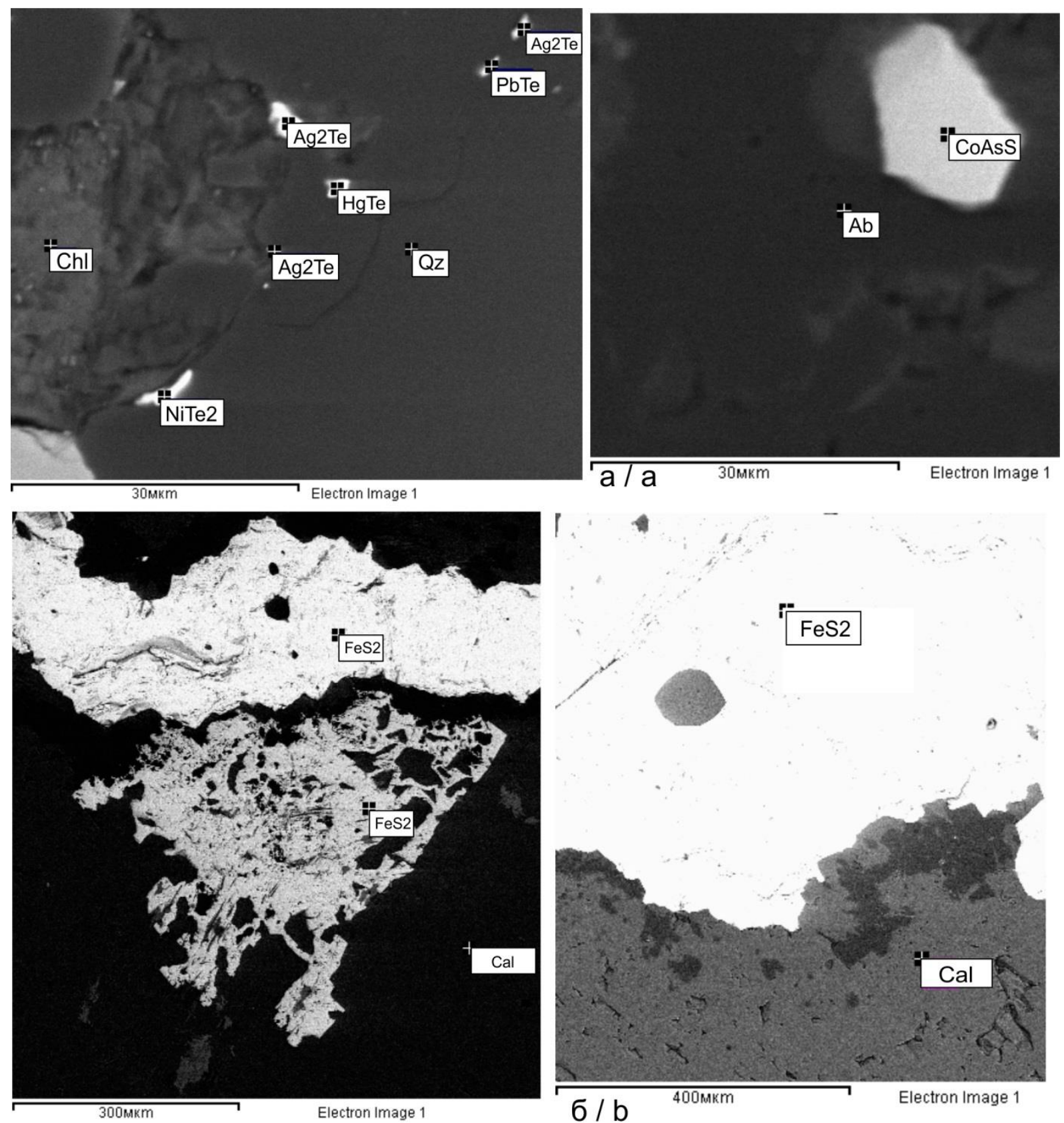

Рис. 5. Онежская параметрическая скважина. Включения кобальтина (CoAsS), гессита ( $\mathrm{gg}_{2} T$ Te), колорадоита (HgTe), мелонита (NiTe 2 ), теллурида свинца (PbTe) в углеродсодержащем алевролите (образеи 3072) с глуби-

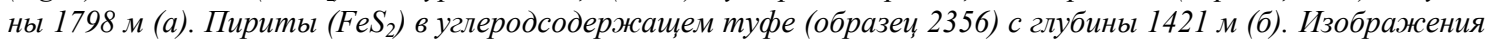
в обратно-отраженных электронах (BSE)

Fig. 5. Onegian parametric well. Inclusions of cobaltin (CoAsS), hessite (Ag2Te), coloradoite (HgTe), melonite (NiTe2), lead telluride $(\mathrm{PbTe})$ in carbonaceous siltstone (sample 3072) from a depth of $1798 \mathrm{~m}\left(\right.$ a). Pyrites $\left(\mathrm{FeS}_{2}\right)$ in carbonbearing tuff (sample 2356) from a depth of $1421 \mathrm{~m}(\mathrm{~b})$. Back-scattered electron (BSE) images 
В воде, контактирующей с шунгитами, возрастает содержание ионов $\left[\mathrm{SO}_{4}\right]^{2}$ (от 23 мг/л в шунгитах I до 130 мг/л в шунгитах II и 52,5 мг/л в шунгитах III), $\mathrm{Cl}^{-}$ (от 39,3 до 38,4 и 90,8 мг/л соответственно), $\mathrm{Na}^{+}, \mathrm{K}^{+}$, продуктов гидролиза железа [41].

При взаимодействии шунгита с водой происходит повышение в воде содержания железа до 1,1 мкг/л при первоначальном содержании его в воде 0,2 мкг/л, марганца до 16 мкг/л при первоначальном содержании его в воде $<10$ мкг/л, меди до 1,5 мкг/л при первоначальном содержании его в воде 1,0 мкг/л, цинка до 242 мкг/л при его первоначальном отсутствии в воде [42].

В настоящее время борьба с примесями шунгитов осуществляется химическим и механическим способами [43]. Учитывая микронные размеры примесного дисульфидного железа и его тончайшую смесь с углеродистым веществом, механический способ очистки здесь работать не будет. Существующий химический способ очистки шунгитов не всегда безопасен. Поэтому шунгитовые фильтры для очистки питьевой воды могут принести не только пользу, но и вред изза присутствия в шунгитах опасных для здоровья микроэлементов.

\section{Заключение}

При взаимодействии шунгитов с водой они обладают разной степенью выщелачивания, то есть выделения из них и поступления в воду химических элементов. Обладая высокой сорбционной способностью, шунгиты могут сорбировать из воды содержащиеся в ней вредные компоненты $[44,45]$. Однако не следует

\section{СПИСОК ЛИТЕРАТУРЫ}

1. Атлас текстур и структур шунгитоносных пород Онежского синклинория / под ред. М.М. Филиппова, В.А. Мележик. Петрозаводск: Карельский научный центр РАН, 2006. - 80 с.

2. Минерально-сырьевая база Республики Карелия. Кн. 2. Неметаллические полезные ископаемые. Подземные воды и лечебные грязи / под ред. В.П. Михайлова, В.Н. Аминова. - Петрозаводск: Карелия, 2006. - 356 с.

3. Reading the archive of Earth's oxygenation. V. 2: The core archive of the Fennoscandian Arctic Russia - Drilling Early Earth Project V.A. Melezhik, A.E. C`rne, A.R. Prave, A. Lepland, A.E. Romashkin, D.V. Rychanchik, E.J. Hanski, A.E. Fallick, P.V. Medvedev, Luo Zh // Series: Frontiers in Earth Sciences. The Onega Basin. - Heidelberg: Springer, 2013. - P. 769-1046.

4. Shungites: the C-rich rocks of Karelia, Russia / P.R. Buseck, L.P. Galdobina, V.V. Kovalevski, N.N. Rozhkova, A.Z. Zaidenberg, J.W. Valley // The Canadian Mineralogist. 1997. - V. 35. - № 6. - P. 1363-1378.

5. Melezhik V.A., Filippov M.M., Romashkin A.E. A giant Palaeoproterozoic deposit of shungite in NW Russia: genesis and practical applications // Ore geology reviews. - 2004. - V. 24. Р. 135-154.

6. Онежская палеопротерозойская структура (геология, тектоника, глубинное строение и минерагения) / отв. ред. Л.В. Глушанин, Н.В. Шаров, В.В. Щипцов. - Петрозаводск: Карельский научный центр РАН, 2011. - 431 с.

7. Общая стратиграфическая шкала нижнего докембрия России Объяснительная записка. - Апатиты: КНЦ РАН, 2002. - 13 с.

8. Сидоренко Св.А. Органическое вещество и биолитогенные процессы в докембрии. - М.: Наука, 1991. - 104 с.

9. Калинин Ю.К., Калинин А.И., Скоробогатов Г.А. Шунгиты Карелии - для новых стройматериалов, в химическом синтезе, газоочистке, водоподготовке и медицине. - СПб: УНЦХ СПбГУ, ВВМ, 2008. - 219 с. забывать о возможности обратного процесса: экстрагирования в воду из шунгитов вредных для человека примесных элементов. Это подтверждают результаты опытов с водными вытяжками лидитов, в составе которых присутствует углерод в виде шунгитового вещества [46]. По приведенным в этой работе данным, при взаимодействии лидита с дистиллированной водой в кислых условиях (pH 4,5-4,6) происходило накопление в экстракте ряда кислоторастворимых элементов - $\mathrm{Sr}, \mathrm{Mn}, \mathrm{U}$ и особенно $\mathrm{Be}, \mathrm{Fe}, \mathrm{Co}, \mathrm{Ni}, \mathrm{Cu}$, $\mathrm{Zn}, \mathrm{Y}, \mathrm{Ba}, \mathrm{Tl}$. В слабощелочных условиях ( $\mathrm{pH} 7,4-7,5)$ наблюдались максимальные концентрации V, Mo, W, $\mathrm{Zr}$ и Hf. Концентрации $\mathrm{Al}$ и $\mathrm{Mn}$ превышали значения ПДК для рыбохозяйственных водоемов. Водные экстракты образцов лидитов показали также превышение «нормы» ПДК таких элементов, как $\mathrm{Fe}, \mathrm{Co}, \mathrm{Ni}, \mathrm{Cu}, \mathrm{Zn}$, $\mathrm{V}$ и Мо.

Как уже отмечалось выше, шунгиты не обладают упорядоченной структурой. Они часто представляют собой тончайшую смесь углеродистого вещества с мельчайшими вкраплениями большей частью сульфидов железа, силикатных минералов. Помимо сульфидов железа в шунгитах отмечены микронные размерности таких минералов, как кобальтин, колорадоит, мелонит и многих других. Встречаются в шунгитовых породах и оксиды свинца, сульфиды цинка.

Существующие в настоящее время методы очистки не позволяют полностью очистить шунгиты от микропримесей, поэтому возможность использования шунгитовых фильтров для очистки питьевой воды остается дискуссионной.

10. Игнатов И.И., Мосин О.В. Состав и структурные свойства природного фуллеренсодержащего минерала шунгита. Математическая модель взаимодействия шунгита с молекулами воды // Интернет-журнал «Науковедение». - 2014. - Вып. 2. URL: http://naukovedenie.ru/PDF/12TVN214.pdf (дата обращения 15.10.2020).

11. Kovalevski V., Shchiptsov V. Shungites and their industrial potential // 14th International Congress for Applied Mineralogy (ICAM2019). Springer Proceedings in Earth and Environmental Sciences. - 2019. - P. 201-204. DOI: 10.1007/978-3-030-22974-0_47.

12. Rozhkova V.S., Kovalevski V.V. Determination of adsorption of cationic and anionic dyes onto shungite by Raman spectroscopy // Spectroscopy. - 2019. - V. 34. - № 7. - P. 45-54.

13. Шунгитовый сорбционный материал для очистки сточных и оборотных вод / С.И. Ануфриева, В.И. Исаев, Ю.Н. Лосев, И.О. Крылов, Н.М. Конышев // Промышленная экология. 2008. - № 4. - C. 28-32.

14. Ануфриева С.И., Ожогина Е.Г. Комплексное изучение шунгитсодержащих и шунгитовых пород участка «Полежаевский» Зажогинского месторождения // Современные методы технологической минералогии в процессе комплексной и глубокой переработки минерального сырья. Материалы международного совещания «Плаксинские чтения». - Петрозаводск, 2012. - С. 238-240.

15. Алюмоматричные композиционные материалы с наполнителями из шунгитовых пород / И.Е. Калашников, В.В. Ковалевский, Т.А. Чернышова, Л.К. Болотова // Металлы. - 2010. № 6. - C. 85-95.

16. Moshnikov I.A., Kovalevski V.V. Composite materials based on nanostructured shungite filler // Materials Today: Proceedings. 2018. - № 11. - Р. 25971-25975.

17. Конюхов И.В. Перспективы использования фуллеренсодержащего сырья в медицинской и фармацевтической практике // Annals of Mechnikov Institute. - 2010. - № 1. - C. 10-14. URL: www.imiamn.org.ua/journal.htm (дата обращения 18.11.2020). 
18. Kipp M.A., Lepland A., Buick R. Redox fluctuations, trace metal enrichment and phosphogenesis in the 2.0 Ga Zaonega Formation // Precambrian Research. - 2020. - V. 343. - P. 105716. DOI: https://doi.org/10.1016/j.precamres.2020.105716.

19. Oxygenated conditions in the aftermath of the Lomagundi-Jatul Event: the carbon isotope and rare earth element signatures of the Paleoproterozoic Zaonega Formation, Russia / T. Kreitsmann, A. Lepland, M. Bau, A. Prave, K. Paiste, K. Mänd, H. Sepp, T. Martma, A.E. Romashkin, K. Kirsimäe // Precambrian Research. 2020. - V. 347. - P. 105855. DOI: https://doi.org/10.1016/ j.precamres.2020.105855.

20. Molybdenum record from black shales indicates oscillating atmospheric oxygen levels in the early Paleoproterozoic / D. Asael, O. Rouxel, S.W. Poulton, T.W. Lyons, A. Bekker // American Journal of Science. - 2018. - V. 318. - P. 275-299. DOI https://doi.org/10.2475/03.2018.01.

21. Multiple sulphur isotope records tracking basinal and global processes in the $1.98 \mathrm{Ga}$ Zaonega Formation, NW Russia / K. Paiste, A. Lepland, A.L. Zerkle, K. Kirsimäe, G. Izon, N.K. Patel, F. McLean, T. Kreitsmann, K. Mänd, T.H. Bui Chemical Geology. - 2018. - V. 499. - P. 151-164. DOI: https://doi.org/10.1016/j.chemgeo.2018.09.025.

22. Identifying global vs. basinal controls on Paleoproterozoic organic carbon and sulfur isotope records / K. Paiste, A. Lepland, A.L. Zerkle, K. Kirsimäe, T. Kreitsmann, K. Mänd, A.E. Romashkin, D.V. Rychanchik, A.R. Prave // Earth-Science Reviews. - 2020. - V. 207. - P. 103230. DOI: https://doi.org/ 10.1016/j.earscirev.2020.103230.

23. The pyrite multiple sulfur isotope record of the $1.98 \mathrm{Ga}$ Zaonega Formation: evidence for biogeochemical sulfur cycling in a semirestricted basin / K. Paiste, A. Pellerin, A.L. Zerkle, K. Kirsimäe, A.R. Prave, A.E. Romashkin, A. Lepland // Earth Planetary Science Letters. - 2020. - V. 534. - P. 116092. DOI https://doi.org/10.1016/j.epsl.2020.116092.

24. Multiple Palaeoproterozoic carbon burial episodes and excursions / A.P. Martin, A.R. Prave, D.J. Condon, A. Lepland, A.E. Fallick, A.E. Romashkin, P.V. Medvedev, D.V. Rychanchik // Earth Planetary Science Letters. - 2015. - V. 424. - P. 226-236. DOI https://doi.org/10.1016/j.epsl.2015.05.023.

25. Pyrite multiple-sulfur isotope evidence for rapid expansion and contraction of the early Paleoproterozoic seawater sulfate reservoir / C. Scott, B.A. Wing, A. Bekker, N.J. Planavsky, P. Medvedev, S.M. Bates, M. Yun, T.W. Lyons // Earth Planetary Science Letters. - 2014. - V. 389. - P. 95-104. DOI https://doi.org/10.1016/j.epsl.2013.12.010.

26. Enhanced Accumulation of Organic Matter: The Shunga Event $/$ H. Strauss, V.A. Melezhik, A. Lepland, A.E. Fallick, E.J. Hanski, M.M. Filippov, Yu.E. Deines, C.J. Illing, A.E. Črne, A.E. Brasier / Reading the Archive of Earth's Oxygenation. V. 3: Global Events and the Fennoscandian Arctic Russia - Drilling Early Earth Project // Series: Frontiers in Earth Sciences. - Heidelberg: Springer, 2013. - P. 1195-1273.

27. Kovalevski V.V., Buseck P.R., Cowley J.M. Comparison of carbon in shungite rocks to other natural carbons: an X-ray and TEM study // Carbon. - 2001. - V. 39. - P. 243-256.

28. Karelian shungite - an indication of 2.0-Ga-old metamorphosed oil-shale and generation of petroleum: geology, lithology and geochemistry / V.A. Melezhik, A.E. Fallick, M.M. Filippov, O. Larsen // Earth-Science Reviews. - 1999. - V. 47. - P. 1-40.

29. Пономарев А.П., Подолец А.А., Макина О.А. Использование водного экстракта минерала шунгита для удаления из воды бактериальной микрофлоры // Водоснабжение и санитарная техника. - 2017. - № 9. - С. 17-24.
30. Пономарев А.П. Водный экстракт минерала шунгита - комплексообразователь для микроорганизмов при очистке водных растворов // Водоснабжение и санитарная техника. 2018. - № 7. - C. 11-17.

31. Роль высокоуглеродистых (шунгитсодержащих) пород в формировании состава подземных вод Онежской структуры / Г.С. Бородулина, С.А. Светов, И.В. Токарев, М.А. Левичев // Труды Карельского научного центра РАН. - 2020. - № 9. C. $72-87$. DOI: 10.17076/lim1259.

32. Рыбаков Д.С. Влияние палеопротерозойских образований Онежской структуры на геохимические особенности почв Заонежья // Труды Карельского научного центра РАН. - 2020. № 10. - C. 72-83. DOI: 10.17076/geo1283.

33. Пономарев А.П. Шунгитовые породы как источник редкоземельных ультрамикроэлементов - лантаноидов // Микроэлементы в медицине. - 2019. - № 20 (2). - С. 55-65.

34. Shungite rocks of varying genesis in innovative water treatment technologies / V.V. Kovalevski, S.-P. Reinikainen, V. Reinikainen, V.S. Rozhkova, T. Sihvonen // Transactions of the Karelian Research Centre of the Russian Academy of Sciences. - 2020. № 6. - P. 97-105. DOI: 10.17076/them1255.

35. Борисов П.А. Карельские шунгиты. - Петрозаводск: Госиздат КФССР, 1956. - $92 \mathrm{c}$

36. Филиппов М.М. Шунгитоносные породы Онежской структуры. - Петрозаводск: КарНЦ РАН, 2002. - 280 с.

37. Ковалевский В.В. Шунгит или высший антраксолит? // Записки РМО. - 2009. - № 5. - С. 97-105.

38. Шунгиты Карелии и пути их комплексного использования / под ред. В.А. Соколова, Ю.К. Калинина. - Петрозаводск, Карелия. 1975. -240 с.

39. Голубев А.И., Ахмедов А.М., Галдобина Л.П. Геохимия черносланцевых комплексов нижнего протерозоя КарелоКольского региона. - Л.: Наука, 1984. - 192 с.

40. Ромашкин А.Е., Рычанчик Д.В., Голубев А.И. Геохимия РЗЭ углеродсодержащих пород Онежской структуры // Геология и полезные ископаемые Карелии. - 2014. - Вып. 17. - С. 74-85.

41. Скоробогатов Г.А., Гончаров Г.Н., Ашмарова Ю.А. Ионообменные и адсорбционные свойства карельских шунгитов, контактирующих с водой // Экологическая химия. - 2012. T. 21. - № 1. - С. 10-16.

42. Бородулина Г.С., Рыжаков А.В. О возможности использования шунгита для очистки водопроводной воды // Научные основы химии и технологии переработки комплексного сырья и синтеза на его основе функциональных материалов: Всероссийская научная конференция с международным участием. Материалы научно-технической конференции. - Апатиты: Изд-во Кольского научного центра РАН, 2008. - Т. 2. - 288 с.

43. Модифицирование шунгитового материала для применения в сорбции и мембранной технологии / И.А. Полунина, И.С. Гончарова, В.В. Высоцкий, Г.А. Петухова и др. // Сорбционные и хроматографические процессы. - 2016. - Т. 16. № 2. - C. 234-240.

44. Сорбционные свойства шунгита / А.С. Шалимов, В.В. Ковалевский, О.Н. Обрезков, А.Б. Ярославцев // Неорганические материалы. - 2004. - № 40 (4). - С. 430-434.

45. Щетинская О.С., Соболева О.А. Очистка сточных вод от соединений хрома с помошью шунгита // Вестник Технологического университета. - 2017. - Т. 20. - № 20. - С. 128-132.

46. Феоктистов В.М., Медведев П.В. Микроэлементный состав водных экстрактов некоторых образцов диатомитов и лидитов Карелии // Известия Томского политехнического университета. Инжиниринг георесурсов. - 2020. - Т. 331. - № 2. - С. 199-205.

Поступила 18.08.2021 2.

\section{Информация об авторах}

Кондрашова Н.И., кандидат геолого-минералогических наук, доцент кафедры наук о Земле и геотехнологий Института лесных, горных и строительных наук Петрозаводского государственного университета; научный сотрудник Института геологии Карельского научного центра РАН.

Медведев П.В., кандидат геолого-минералогических наук, доцент кафедры наук о Земле и геотехнологий Института лесных, горных и строительных наук Петрозаводского государственного университета; старший научный сотрудник Института геологии Карельского научного центра РАН. 
UDC 550.4.02

\title{
CARBON BEARING ROCKS (SHUNGITES). ARE THEY SO SAFE FOR DRINKING WATER PURIFICATION?
}

\author{
Natalia I. Kondrashova ${ }^{1,2}$, \\ kondr@krc.karelia.ru \\ Pavel V. Medvedev ${ }^{1,2}$, \\ pmedved@krc.karelia.ru \\ 1 Petrozavodsk State University, \\ 33, Lenin avenue, Petrozavodsk, 185910, Russia. \\ 2 Karelian Research Centre of RAS, \\ 11, Pushkinsky street, Petrozavodsk, 185910, Russia.
}

The relevance of the study is caused by the need to obtain consistent information about the possibility of using carbonaceous sedimentary rocks of shungite for drinking water purification. Currently, shungite is used in many industries, their effectiveness has been proven in the treatment of wastewater from organic and oil products. Using the high adsorption capacity of shungite, a number of authors, without good reason, recommend using shungite for purification of water for domestic and drinking use.

Purpose: to study the microelement composition of shungite, to assess the possibility of introducing microelements harmful to humans into an aqueous solution of shungite.

Objects: samples of shungite from the Paleoproterozoic successions of the Onegian paleobasin, Karelia.

Methods: scanning electron microscopy, chemical analysis, Inductively Coupled Plasma Mass Spectrometry (ICP-MS).

Results. The macro- and microelement composition of shungites of the Paleoproterozoic of the Onegian paleobasin (Karelia) has been studied. The sulfides and accessory minerals of shungite contain trace elements of various dimensions that are harmful to humans. Their mineral composition mainly consists of quartz (25-65\%), sericite, chlorite, pyrite, carbonate. The organic carbon content varies from 21 to $45 \%$. Pyrite is present both in the form of nodules and in micro-veins. In addition to pyrite sulphides of zinc, cobaltite, lead oxides are observed. Macroelements ( $\mathrm{Si}, \mathrm{Ti}, \mathrm{Al}, \mathrm{Fe}, \mathrm{Mn}, \mathrm{Ca}, \mathrm{Mg}, \mathrm{Na}, \mathrm{K}$ ) found in the chemical composition of shungites are mainly part of rockforming minerals. In addition to macroelements, shungites contain a significant number of trace elements associated with accessory minerals and sulfides of various dimensions. These are $\mathrm{S}, \mathrm{As}, \mathrm{V}, \mathrm{Co}, \mathrm{Ni}, \mathrm{Cr}, \mathrm{Cu}, \mathrm{Zn}, \mathrm{Mo}, \mathrm{Ge}, \mathrm{B}, \mathrm{Sr}, \mathrm{Li}, \mathrm{Pb}$, rare earth elements. In the shungites of the Zazhogino Deposit, the chromium content varies from 96 to 151 ppm, the nickel content varies from 102 to $259 \mathrm{ppm}$. In carbon rich rocks of the Maksovo Deposit chromium is present in the amount of 103-144 ppm, nickel concentrations are determined in the range of 47-196 ppm. For the Shunga Deposit, these values are as follows: $\mathrm{Cr}$ is present in an amount of 74-137 ppm, Ni content varies from 86 to $275 \mathrm{ppm}$. The sulfides and accessory minerals of shungite contain trace elements of various dimensions that are harmful to humans. Having a high sorption capacity, shungite can absorb harmful components from water. At the same time, the reverse process also occurs - the extraction of impurity elements harmful to humans from shungite. The currently existing methods for purifying shungites do not allow them to be purified from micro impurities, therefore, the question of using shungites for treatment of drinking water supply remains open.

\section{Key words:}

Shungite, trace element composition, Karelia, Onegian paleobasin, Ludikovian, Paleoproterozoic.

\section{REFERENCES}

1. Atlas tekstur $i$ struktur shungitonosnykh porod Onezhskogo sinklinoriya [Atlas of textures and structures of shungite-bearing rocks of the Onego synclinorium]. Eds. M.M. Filippov, V.A. Melezhik. Petrozavodsk, Karelia scientific center RAN Publ. 2006. $80 \mathrm{p}$.

2. Mineralno-syrevaya baza Respubliki Kareliya. Kn. 2. Nemetallicheskie poleznye iskopaemye. Podzemnye vody lechebnye gryazi [Mineral resource base of the Republic of Karelia B. 2. Industrial minerals. Groundwater and medicinal mud]. Eds. V.P. Mikhailov, V.N. Aminov. Petrozavodsk, Kareliya Publ., 2006 $356 \mathrm{p}$.

3. Melezhik V.A., C'rne A.E., Prave A.R., Lepland A., Romashkin A.E., Rychanchik D.V., Hanski E.J., Fallick A.E., Medvedev P.V., Luo Zh. The Onega Basin. Reading the Archive of Earth's Oxygenation. Vol. 2: The Core Archive of the Fennoscandian Arctic Russia - Drilling Early Earth Project. Series: Frontiers in Earth Sciences. Heidelberg, Springer, 2013. pp. 769-1046.

4. Buseck P.R., Galdobina L.P., Kovalevski V.V., Rozhkova N.N., Zaidenberg A.Z., Valley J.W. Shungites: the C-rich rocks of Karelia, Russia. The Canadian Mineralogist, 1997, vol. 35, no. 6, pp. 1363-1378.

5. Melezhik V.A., Filippov M.M., Romashkin A.E. A giant Palaeoproterozoic deposit of shungite in NW Russia: genesis and practical applications. Ore geology reviews, 2004, vol. 24, pp. 135-154.

6. Onezhskaya paleoproterozoiskaya struktura (geologiya, tektonika, glubinnoe stroenie $i$ minerageniya) [Onegian Paleoproterozoic basin (geology, tectonics, deep structure and minerageny)]. Eds. L.V. Glushanin, N.V. Sharov, V.V. Shchiptsov. Petrozavodsk, Karelia scientific center RAN Publ., 2011. 431 p.

7. Obshchaya stratigraficheskaya shkala nizhnego dokembriya Rossii. Obyasnitelnaya zapiska [General stratigraphic scale of the Lower Precambrian for Russia. Explanatory note]. Apatity, Kola Scientific Center of RAS Publ., 2002. 13 p.

8. Sidorenko Sv.A. Organicheskoe veshchestvo $i$ biolitogennye protsessy $v$ dokembrii [Organic matter and biolithogenic processes in the Precambrian]. Mosow, Nauka Publ., 1991. 104 p.

9. Kalinin Yu.K., Kalinin A.I., Skorobogatov G.A. Shungity Kareliidlya novykh stroimaterialov, v khimicheskom sinteze, gazoochistke, vodopodgotovke $i$ meditsine [Shungites of Karelia - for new building materials, in chemical synthesis, gas purification, water treatment and medicine]. St-Petersburg, UNTSKH SPBGU, VVM Publ., 2008. 219 p.

10. Ignatov I.I., Mosin O.V. Sostav i strukturnye svoystva prirodnogo fullerensoderzhashchego minerala shungita. Matematicheskaya model vzaimodeistviya shungita s molekulami vody [Composition and structural properties of natural fullerene-containing mineral shungite. Mathematical model of the interaction of shungite with 
water molecules]. Internet-zhurnal «Naukovedenie», 2014, Iss. 2 In Rus. Available at: http://naukovedenie.ru/PDF/12TVN214.pdf (accessed 15 October 2020)

11. Kovalevski V., Shchiptsov V. Shungites and their industrial potential. $14^{\text {th }}$ International Congress for Applied Mineralogy (ICAM2019). Springer Proceedings in Earth and Environmental Sciences, 2019, pp. 201-204. DOI: 10.1007/978-3-030-22974-0_47.

12. Rozhkova V.S., Kovalevski V.V. Determination of adsorption of cationic and anionic dyes onto shungite by Raman spectroscopy. Spectroscopy, 2019, vol. 34, no. 7, pp. 45-54.

13. Anufrieva S.I., Isaev V.I., Losev Yu.N., Krylov I.O., Konyshev N.M. Shungitovy sorbtsionny material dlya ochistki stochnykh i oborotnykh vod [Shungite sorption material for waste and recycling water treatment]. Promyshlennaya ehkologiya, 2008, no. 4 , pp. 28-32.

14. Anufrieva S.I., Ozhogina E.G. Kompleksnoe izuchenie shungitsoderzhashchikh i shungitovykh porod uchastka «Polezhaevsky» Zazhoginskogo mestorozhdeniya [Comprehensive study of shungite-bearing and shungite rocks of the Polezhaevsky site of the Zazhoginskoe deposit]. Sovremennye metody tekhnologicheskoy mineralogii v protsesse kompleksnoy i glubokoy pererabotki mineralnogo syrya. Materialy mezhdunarodnogo soveshchaniva "Plaksinskie chteniya» [Modern methods of technological mineralogy in complex deep processing mineral raw material. Materials of International meeting. Plaksin readings] Petrozavodsk, 2012. pp. 238-240.

15. Kalashnikov I.E., Kovalevskii V.V., Chernyshova T.A., Bolotova L.K Aluminum-matrix composite materials with shungite fillers. Metally, 2010, no. 6, pp. 85-95. In Rus.

16. Moshnikov I.A., Kovalevski V.V. Composite materials based on nanostructured shungite filler. Materials Today: Proceedings, 2018, no. 11, pp. 25971-25975.

17. Konyukhov I.V. Prospects for the use of fullerene-containing raw materials in medical and pharmaceutical practice. Annals of Mechnikov Institute, 2010, no. 1, pp. 10-14. In Rus. Available at: www.imiamn.org.ua/journal.htm (accessed 18 November 2020).

18. Kipp M.A., Lepland A., Buick R. Redox fluctuations, trace metal enrichment and phosphogenesis in the $2.0 \mathrm{Ga}$ Zaonega Formation Precambrian Research, 2020, vol. 343, pp.105716. DOI https://doi.org/10.1016/j.precamres.2020.105716.

19. Kreitsmann T., Lepland A., Bau M., Prave A., Paiste K., Mänd K., Sepp H., Martma T., Romashkin A.E., Kirsimäe K. Oxygenated conditions in the aftermath of the Lomagundi-Jatuli Event: the carbon isotope and rare earth element signatures of the Paleoproterozoic Zaonega Formation, Russia. Precambrian Research, 2020, vol. 347, pp. 105855. DOI: https://doi.org/10.1016/j.precamres. 2020.105855.

20. Asael D., Rouxel O., Poulton S.W., Lyons T.W., Bekker A. Molybdenum record from black shales indicates oscillating atmospheric oxygen levels in the early Paleoproterozoic. American Journal of Science, 2018, vol. 318, pp. 275-299. DOI: https://doi.org/10.2475/03.2018.01.

21. Paiste K., Lepland A., Zerkle A.L., Kirsimäe K., Izon G., Patel N.K., McLean F., Kreitsmann T., Mänd K., Bui T.H. Multiple sulphur isotope records tracking basinal and global processes in the 1.98 Ga Zaonega Formation, NW Russia. Chemical Geology, 2018, vol. 499, pp. 151-164. DOI: https://doi.org/10.1016/j.chemgeo. 2018.09.025

22. Paiste K., Lepland A., Zerkle A.L., Kirsimäe K., Kreitsmann T., Mänd K., Romashkin A.E., Rychanchik D.V., Prave A.R. Identifying global vs. basinal controls on Paleoproterozoic organic carbon and sulfur isotope records. Earth-Science Reviews, 2020, vol. 207, pp. 103230. DOI: https://doi.org/10.1016/j.earscirev.2020.103230.

23. Paiste K., Pellerin A., Zerkle A.L., Kirsimäe K., Prave A.R., Romashkin A.E., Lepland A. The pyrite multiple sulfur isotope record of the $1.98 \mathrm{Ga}$ Zaonega Formation: evidence for biogeochemical sulfur cycling in a semi-restricted basin. Earth Planetary Science Letters, 2020, vol. 534. DOI: https://doi.org/10.1016/j.epsl. 2020.116092.

24. Martin A.P., Prave A.R., Condon D.J., Lepland A., Fallick A.E., Romashkin A.E., Medvedev P.V., Rychanchik D.V. Multiple Palaeoproterozoic carbon burial episodes and excursions. Earth Planetary Science Letters, 2015, vol. 424, pp. 226-236. DOI: https://doi.org/10.1016/j.epsl.2015.05.023.
25. Scott C., Wing B.A., Bekker A., Planavsky N.J., Medvedev P., Bates S.M., Yun M., Lyons T.W. Pyrite multiple-sulfur isotope evidence for rapid expansion and contraction of the early Paleoproterozoic seawater sulfate reservoir. Earth Planetary Science Letters, 2014, vol. 389, pp. 95-104. DOI: https://doi.org/10.1016/ j.epsl.2013.12.010.

26. Strauss H., Melezhik V.A., Lepland A., Fallick A.E., Hanski E.J, Filippov M.M., Deines Yu.E., Illing C.J., Črne A.E., Brasier A.E. Enhanced Accumulation of Organic Matter: The Shunga Event. Reading the Archive of Earth's Oxygenation. Vol. 3: Global Events and the Fennoscandian Arctic Russia - Drilling Early Earth Project. Series: Frontiers in Earth Sciences. Heidelberg, Springer, 2013. pp. 1195-1273.

27. Kovalevski V.V., Buseck P.R., Cowley J.M. Comparison of carbon in shungite rocks to other natural carbons: an X-ray and TEM study. Carbon, 2001, vol. 39, pp. 243-256.

28. Melezhik V.A., Fallick A.E., Filippov M.M, Larsen O. Karelian shungite - an indication of 2.0-Ga-old metamorphosed oil-shale and generation of petroleum: geology, lithology and geochemistry. Earth-Science Reviews, 1999, vol. 47, pp. 1-40.

29. Ponomarev A.P., Podolets A.A., Makina O.A. The use of an aqueous extract of shungite mineral to remove bacterial microflora from water. Vodosnabzhenie i sanitarnaya tekhnika, 2017, no. 9, pp. 17-24. In Rus.

30. Ponomarev A.P. Aqueous extract of shungite mineral - a complexing agent for microorganisms in the purification of aqueous solutions. Vodosnabzhenie i sanitarnaya tekhnika, 2018, no. 7, pp. 11-17. In Rus.

31. Borodulina G.S., Svetov S.A., Tokarev I.V., Levichev M.A. The role of high-carbon content (shungite-bearing) rocks in the formation of the composition of groundwater in the Onegian paleobasin. Trudy Karelskogo nauchnogo tsentra RAN, 2020, no. 9 , pp. 72-87. In Rus. DOI: 10.17076/lim1259.

32. Rybakov D.S. Influence of the Paleoproterozoic formations of the Onegian basin on the geochemical characteristics of the soils in Zaonezhie. Trudy Karelskogo nauchnogo tsentra RAN, 2020, no. 10, pp. 72-83. In Rus. DOI: 10.17076/geo1283.

33. Ponomarev A.P. Shungite rocks as a source of rare earth ultramicroelements - lanthanides. Mikroehlementy v meditsine, 2019, no. 20 (2), pp. 55-65. In Rus.

34. Kovalevski V.V., Reinikainen S.-P., Reinikainen V., Rozhkova V.S., Sihvonen T. Shungite rocks of varying genesis in innovative water treatment technologies. Transactions of the Karelian Research Centre of the Russian Academy of Sciences, 2020, no. 6, pp. 97-105. DOI: 10.17076/them1255.

35. Borisov P.A. Karelskie shungity [Karelian shungites]. Petrozavodsk, Gosizdat KFSSR, 1956. 92 p.

36. Filippov M.M. Shungitonosnye porody Onezhskoi struktury [Shungite-bearing rocks of the Onega structure]. Petrozavodsk, KaRNTS RAN Publ., 2002. 280 p.

37. Kovalevskii V.V. Shungite or higher anthraxolite?. Zapiski RMO, 2009, no. 5, pp. 97-105. In Rus.

38. Shungity Karelii i puti ikh kompleksnogo ispolzovaniya [Shungites of Karelia and ways of their complex use]. Eds. V.A. Sokolova, Yu.K. Kalinina. Petrozavodsk, Kareliya Publ., 1975. 240 p.

39. Golubev A.I., Akhmedov A.M., Galdobina L.P. Geokhimiya chernoslantsevykh kompleksov nizhnego proterozoya KareloKolskogo regiona [Geochemistry of Lower Proterozoic Black Shale Complexes in the Karelo-Kola Region]. Petrozavodsk, Nauka Publ., 1984. 192 p.

40. Romashkin A.E., Rychanchik D.V., Golubev A.I. Geokhimiya RZE uglerodsoderzhashchikh porod Onezhskoy struktury [REE geochemistry of carbon-bearing rocks of the Onegian paleobasin]. Geologiya i poleznye iskopaemye Karelii, 2014, vol. 17, pp. 74-85.

41. Skorobogatov G.A., Goncharov G.N., Ashmarova Yu.A. Ionoobmennye $\mathrm{i}$ adsorbtsionnye svoistva karelskikh shungitov, kontaktiruyushchikh s vodoy [Ion exchange and adsorption properties of Karelian shungites in contact with water]. Ehkologicheskaya khimiva, 2012, vol. 21, no. 1, pp. 10-16.

42. Borodulina G.S., Ryzhakov A.V. O vozmozhnosti ispolzovaniya shungita dlya ochistki vodoprovodnoy vody [On the possibility of using shungite for tap water purification]. Nauchnye osnovy khimii i tekhnologii pererabotki kompleksnogo syrya i sinteza na ego osnove funktsionalnykh materialov. Vserossiiskaya nauchnaya konferentsiya s mezhdunarodnym uchastiem. Materialy nauchno- 
tekhnicheskoy konferentsii [Scientific bases of chemistry and technology of processing of complex raw materials and synthesis on its basis of functional materials. All-Russian scientific conference with international participation. Proceedings of the scientific and technical conference]. Apatity, KSC RAN Publ., 2008. Vol. 2, pp. 288

43. Polunina I.A., Goncharova I.S., Vysotskii V.V., Petukhova G.A. Modifitsirovanie shungitovogo materiala dlya primeneniya $v$ sorbtsii i membrannoi tekhnologii [Modification of shungite material for use in absorption and membrane technology]. Sorbtsionnye i khromatograficheskie protsessy, 2016, vol. 16, no. 2, pp. 234-240. In Rus.
44. Shalimov A.S., Kovalevskii V.V., Obrezkov O.N., Yaroslavtsev A.B. Absorption properties of shungite. Neorganicheskie materialy, 2004, no. 40 (4), pp. 430-434. In Rus.

45. Shchetinskaya O.S., Soboleva O.A. Wastewater treatment from chromium compounds using shungite. Vestnik Tekhnologicheskogo universiteta, 2017, vol. 20, no. 20, pp. 128-132. In Rus.

46. Feoktistov V.M., Medvedev P.V. Trace element composition of aqueous extracts of some diatomite and lydite samples from Karelia. Bulletin of the Tomsk Polytechnic University. Geo assets Engineering, 2020, vol. 331, no. 2, pp. 199-205. In Rus.

Received: 18 August 2021.

Information about the authors

Natalia I. Kondrashova, Cand Sc., associate professor, Petrozavodsk State University; researcher, Institute of Geology, Karelian Research Centre of RAS.

Pavel V. Medvedev, Cand Sc., associate professor, Petrozavodsk State University; senior researcher, Institute of Geology, Karelian Research Centre of RAS. 